DE DE GRUYTER

OPEN

DOI: 10.2478/aa-2014-0009

\title{
Pictures in Words - Kanji, Images in Literature - Sōshi
}

\section{Sandra-Lucia Istrate}

Sandra-Lucia Istrate, Associate Professor, teaches Japanese Literature, Culture and Civilization at Hyperion University in Bucharest and the Romanian-Japanese Studies Center; she is also Dean of the Faculty of Social, Humanistic and Natural Studies, a member of the Association of Japanese Language Teachers in Romania. She received a Master's degree in International Relations (Political Science, Bucharest University, 2004) with a dissertation on EU-Japan Trade and Economy and a $\mathrm{PhD}$ in Philology (Philology, Bucharest University, 2009), with a thesis on Japanese Folklore; in 2010 she studied Methods of Teaching Japanese at the Japanese-Language Institute, Urawa, Japan. She is the author of Romanian Traditions (Nodashi Zasshi, 2009), New Year in Japan (Saitama International, 2009), Romania and Japan (Nodashi Zasshi, 2006), Romanian Folklore (Nodashi Zasshi, 2007), Conversation Guide-Book (Romanian - English - Japanese - Italian) (Perpessicius, 2009).

\begin{abstract}
From ancient times, the Japanese have been exploiting the image in as many ways as possible. They have used it in linguistics, literature, art - and the list is certainly much longer. Thus, the first part of my work tries to explain the importance of the kanji writing system and the "image" of a kanji, so that readers who do not understand the Japanese language can become familiar with it (origin, structure, mnemotechnics etc.). The second part of my work explains that later, in the 14th century, when "sōshi" or "zōshi" literature was born, n all of its books the relation between the text and the image was more than important. In the end, I conclude that the "image" is a defining element in understanding Japanese language and literature even in the 21 st century.
\end{abstract}

From ancient to contemporary times, Japanese people have exploited the image in many different possible ways. From the time they started to use - in the 5th century - and then transformed the old Chinese characters that became a means of written communication, to the creation of origami, the art of paper folding (giving rise to a multitude of "images" that can represent an overwhelming diversity of elements of the surrounding environment, rooted in the Heian Period ${ }^{\mathrm{i}}$ and now widespread in all countries in multicultural exchange programmes), to $s \overline{o s h i} / z \bar{o} s h i$ stories, originally appearing in the 14th century, the image not only prevails but is absolutely necessary to understanding the story. Thus, we have to deal with three different types of image that may give birth to the same number of communication means. The image always outputs "something" and that "something" always turns into communication, a sine qua non element of our existence. Thus, an image of a ikebana flower arrangement or a print on a kimono may display moments of the seasons; pictures drawn in comic books - mangashow what type of audience a particular book is addressed to; not to mention the image of Hokusai's Wave $e^{\mathrm{ii}}$ that gave rise to the wonderful feelings that inspired Debussy, or Japanese gardens images, arranged in the karesansui style, in which drawings on sand or ones made with small stones may suggest the sea or wonderful islands. Starting from the Japanese proverb "A simple picture says more than a thousand words", I consider that the exploitation of an image may be performed at any level and it can lead to all possible types of 
communication, whereas the whole universe and everything related to it represents an infinity of images. And any image representing "something" may "talk", communicate messages, and express thoughts or feelings. The examples are plentiful, and that's why I will summarize the main theme which discusses the image as a defining element in understanding Japanese language and literature.

Regarding Japanese characters - kanjiii - images can be used both for teaching purposes, to explain their origin, as well as mnemonically, indicating some methods that can help in memorizing them. Kanji are originally Chinese ancient characters and appeared more than 3,000 years ago. Initially they represented simple illustrations of objects, natural phenomena or activities of daily life and, in time, they turned into written communication methods, characterized primarily by pictographic and ideographic elements. Thus, each character has a meaning of its own.

Ancient Chinese characters or kanji are also classified considering their origin and structure.

For example, there are characters - pictograms - derived from forms of concrete objects. Each image shows the immediate meaning of the character that derives from it. Therefore, the final graphic "product" is based and born from a simple "painting" in this context - the "image" and similarity of the two is striking. Determination of the final "product" is indeed a very logical one, so it is very easy to understand and remember.

1. $\operatorname{sun} / h i$

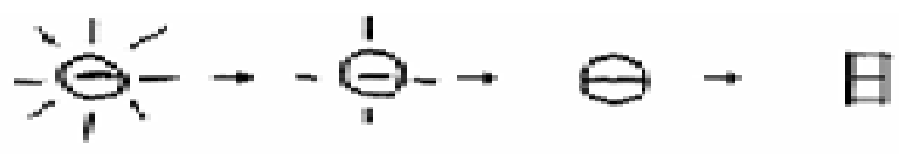

2. $\mathrm{moon} /$ tsuki

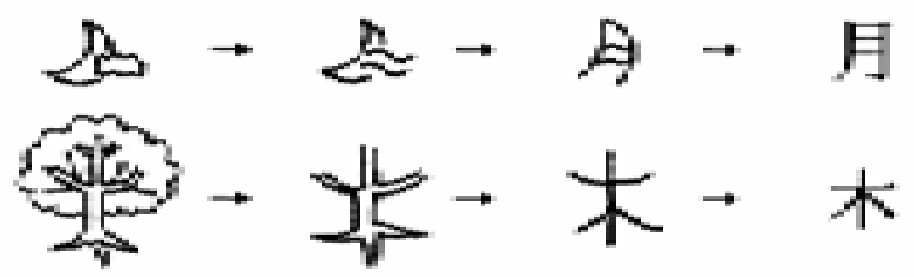

3. $\operatorname{tree} / k i$

4. mountain/yama

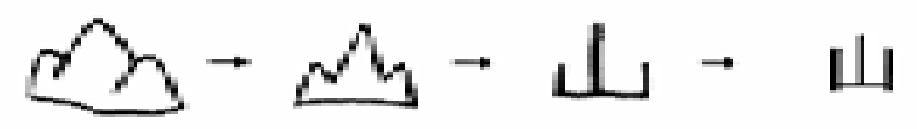

5. river/kawa

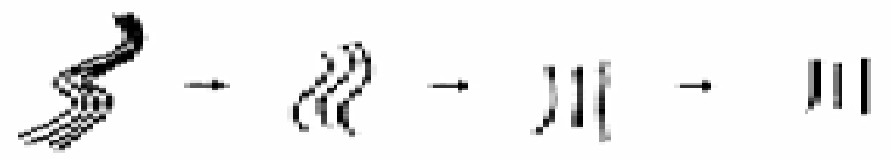

6. field/ta

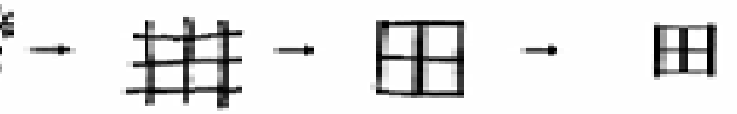

7. person/hito

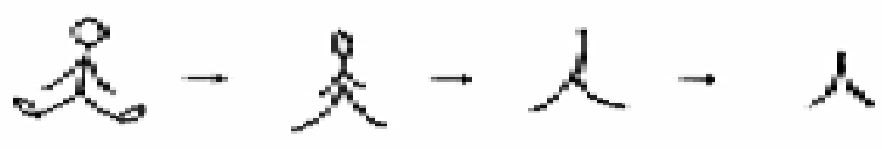

8. mouth/kuchi

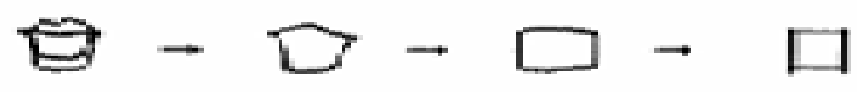

9. car/kuruma

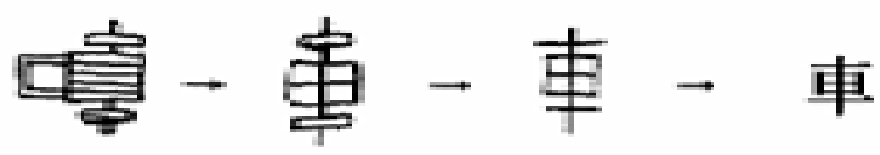

10. gate/kado

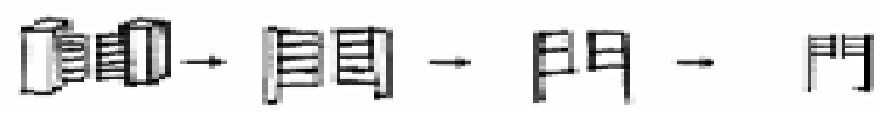


(Nishiguchi Koichi and Kono Tamaki 1994)

Simple ideograms or characters are composed of dots, points and lines to express abstract ideas. In this case we can easily realize the significance of the image. The point above the line indicates that there is "something" on a certain place in the space, and the point below the line indicates that there is "something" under a certain place in the space.

1. on/ue

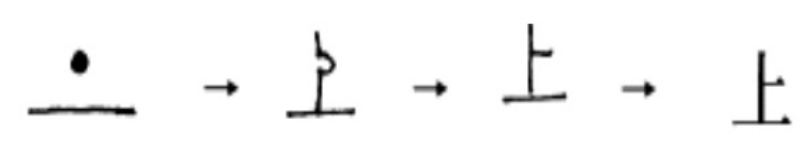

2. under/shita

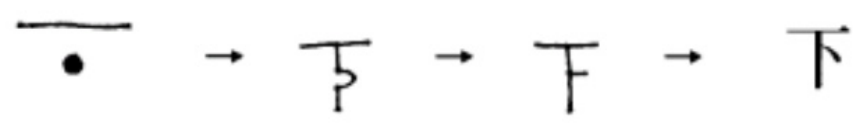

(Nishiguchi Koichi and Kono Tamaki 1994)

Compound ideograms consist of a combination of other characters. The juxtaposition of characters creates a different character here, but also here, the meaning of the last one can be easily interpreted by logical deduction:

木 tree/ki+木 tree/ki= 林 grove/ hayashi (few trees in a place)

林 grove/hayashi + 木 tree/ki $=$ 森 forest, wood/mori (more trees in a place)

日 $\operatorname{sun} / h i+$ 月 $\mathrm{moon} /$ tsuki $=$ 明 bright, light / aka(rui)(both sun and moon are bright and they give light)

人 $\rightarrow$ person/ hito + 木 tree/ki $=$ 休 rest/ yasumi (a person that has some rest under the shadow of a tree)

A kanji may be composed of two or more elements, and parts of a kanji may appear in various combinations of other kanji. Some parts of them, common to several characters, are called radicals (bushu). Each radical has a basic meaning. Here we can find the role of the image. The "view" of such a radical can indicate precisely the meaning of the word (Itasaka, 1993, p.91). The radical for "word" can be found in kanji used for "language", "story", "to talk", "to read", "to take notes", "to discuss", and "to forgive/excuse". However, they have something in common with the radical of "word". Or the radical "rain", which is used for more words related to rain, or weather, such as "thunder", "snow", "frost", "cloud". This kanji is included in the phonetic ideograms category. 
語/ language

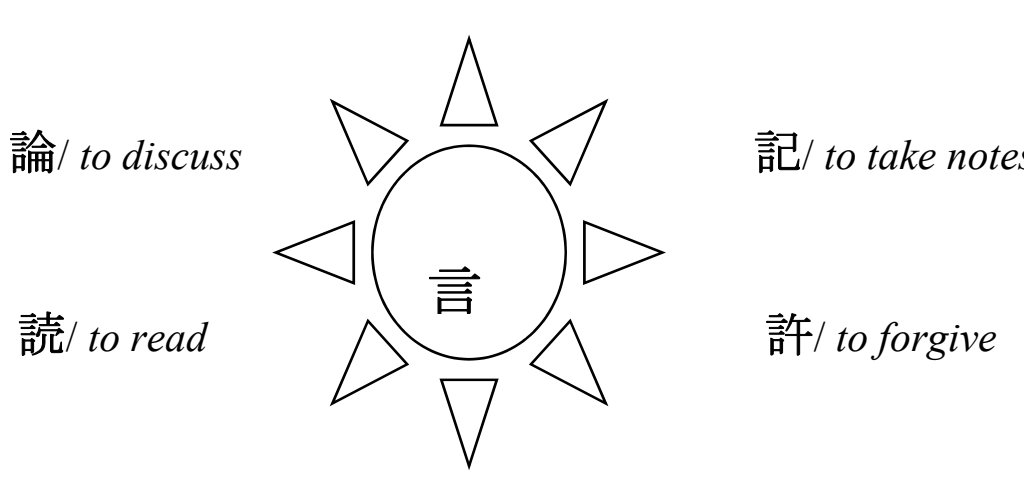

話 story/ to tell a story/to talk

雲/ cloud

2

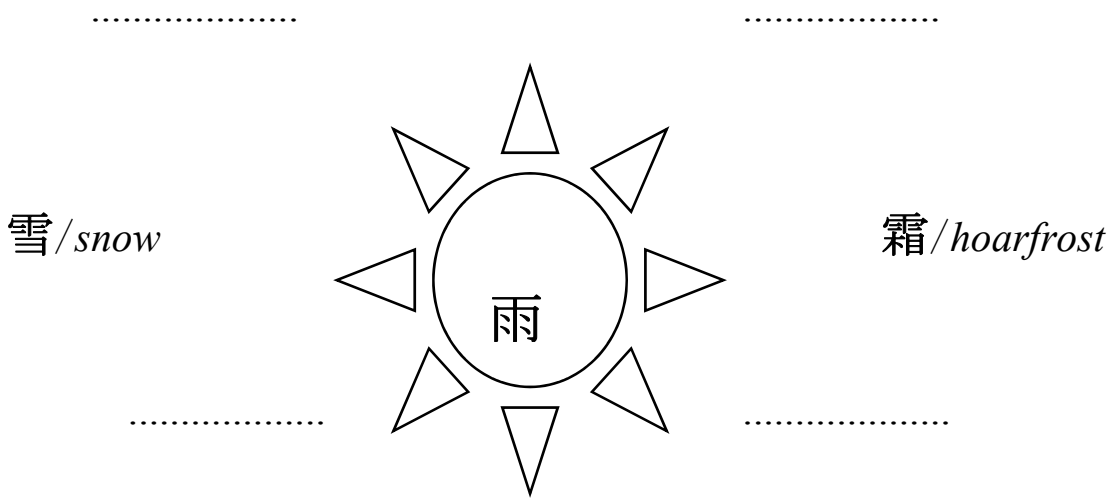

雷 / thunder

Mnemonic methods applied in studying kanji are really very helpful. Very often it is easy to remember a kanji if we try to find its logical content or if we can find some correlations. For example, regarding the characters used for "right" and "left", we have the following explanations: "right" combines the elements of "hand" and "mouth" - people generally eat with their right hand, and "left" combines the elements of "hand" and "carpenter's ruler" - a carpenter's ruler is always kept in the left hand, so he can use the right one to mark.

Right 右 = ナhand + 口 mouth 
Left 左 $=$ ナ hand + 工 ruler

It is very interesting to notice that some kanji may have and/or show, besides an obvious graphical logic, some references regarding mythological, historical, religious or social sources, maintaining and preserving the past so far, which is particularly important for the contemporary generation and continuous development of its cultural knowledge.

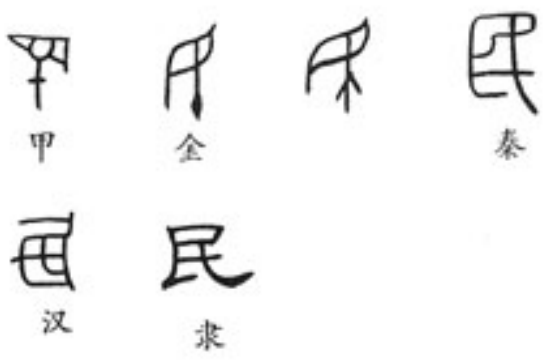

民 (min, tami) is the kanji for "nation", and "people". This character was born in the form of an eye pricked by a needle. There is a theory that some slaves became blind after their leader pricked their eyes with a needle. These blind people were called $\min$ or tami and were seen as servants of the gods.

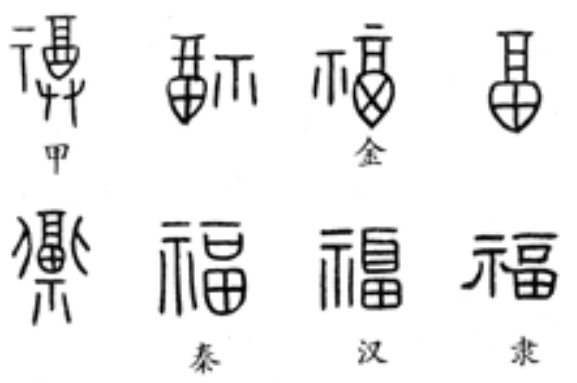

福 (fuku, saiwai) is the kanji for "good luck"/ "fortune".

It combines the shape of a wine cask on the right side, and one of a table on the left. Thus, people put on the table some sake and offered it to the gods, while praying for happiness. This happiness, called fuku, is actually divine help and protection of the gods.

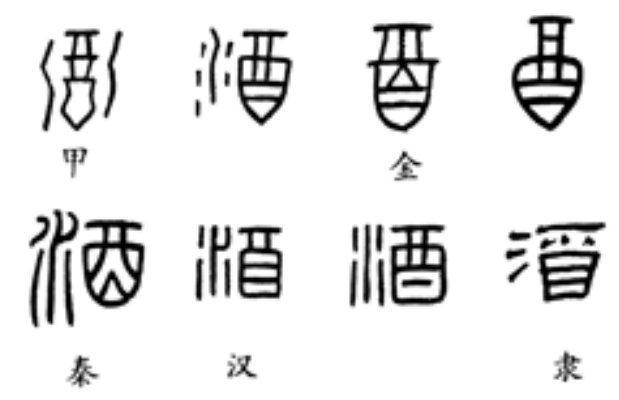

酒 (shu, sake, saka) is the kanji for "alcohol". Yū, the Rooster from the Chinese Zodiac takes the form of a bin (recipient) for alcohol and the radical sanzui, which refers to water, is added to it. Therefore, by derivation, they give birth to the kanji for "alcohol". In the times of the 
Yin Dynasty ${ }^{\text {iv }}$, when organizing festivals, people used to drink a lot of alcohol and it is said that this was why the dynasty was ruined and destroyed.

The number of characters is overwhelming and the multitude of their interpretation, too. To be able to memorize and interpret them sometimes a little imagination and visual memory are needed, but very often, especially in their interpretation, the cultural level of a person may have more influence. This difficulty and the multitude of interpretations grant an important role to the image that has always had a decisive place in Japanese culture. In ancient times, everything may have been guessed, supposed or interpreted from images. They were sometimes accompanied by words that added some information, but the image was the one that spoke first, gave information and let the imagination of the observer decide cognitively what he could really see.

The text-image relationship is well defined in $s \bar{s} s h i$ ( $\sim$ zōshi by consonant alternation), books of short stories both for children and adults, which emerged in the late 14th century, and where images were prevalent and transmitted detailed information about the subject of the story and its characters. The expressiveness of images forced the text into second place, in an inferior position, and moreover, sometimes this text did not make any sense when it appeared by itself, without images. In other words, the images/pictures in the book were so expressive that the presence of the text was only an additional element. Frequently, the placement in time/epoque or season, physiognomy, main features or mentality of the characters, specific architectural elements or particularities of an epoque were not expressed or described in script, but only graphically.

Sōshi can be classified into four categories: otogizōshi, kanazōshi, ukiyozōshi, kusazōshi.

Otogizōshi (御伽 草子) appeared in the 14th century as novels or medieval stories, with subjects regarding the samurai class, then aristocracy, religion, or retelling of legends and fairy tales. Some of them had an absolute didactic purpose, but most of them, on the contrary, could be browsed for fun and admiration of the drawings, in total moments of relaxation. The presence of images made the text poor and therefore expression was simple and description was concise. In general, themes were already known, and the action took place around one main character, usually, a heroic one.

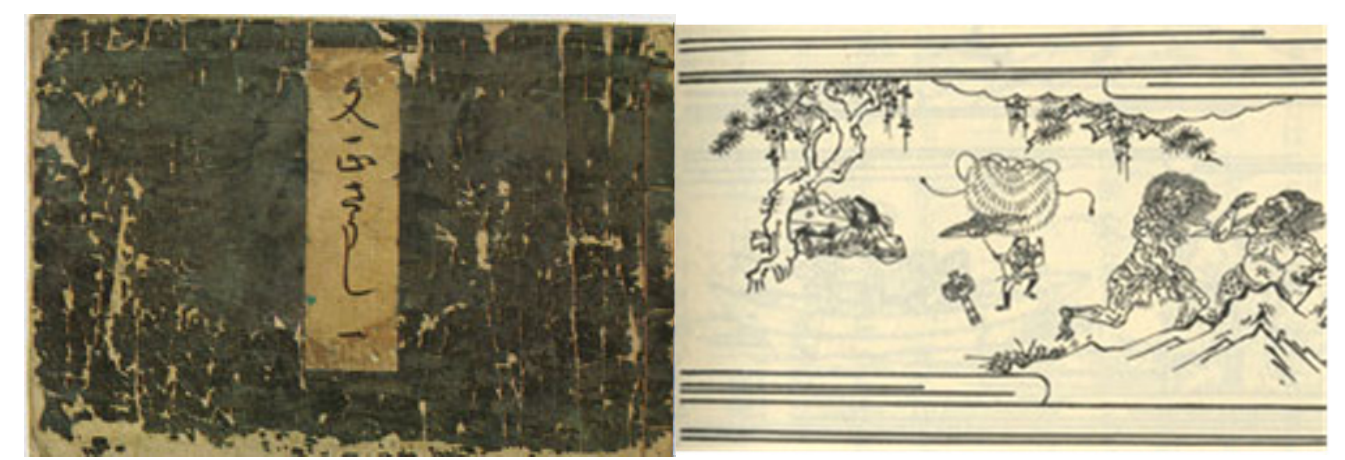

Fig.1.

Fig.2.

Fig. 1. The cover of a volume issued in the 8th century, part of Shîgen otogibunko, published by Shibukawa Kiyoemon. (Source:http://www.artforgers.com/tag.cfm?id=Shibukawa_Kiyoemon)

Fig. 2. Illustration from Issun bôshi, published in 1725 by Shibukawa Kiyoemon. Unknown artist.(Source: http://en.wikipedia.org/wiki/File:Otogizoshi5.jpg)

Before 1620, the only books in Japan were manuscripts. Printing kanazōshi (仮名草子) was not prohibitively expensive and it was more accessible than the manuscripts. Therefore, kanazōshi are considered the first example of commercial literature produced in Japan. Their 
popularity was not that widespread because they were relatively expensive for the common man (four days' pay). That's why the few hundred copies printed in those times were not enough to spread beyond the borders of Kyōto, Ōsaka and Edo, which in that time were the only places in Japan where printing centres existed. They were issued initially in Kyōto, in 1620 , and their name actually means "books written in kana" ("easy to read"), because of the absence of kanji. At the same time they were considered a transitional literary genre that filled the gap created between the romantic medieval adventures in the Edo period ${ }^{\mathrm{v}}$ and Ihara Saikaku $^{\mathrm{vi}}$, $\mathrm{s} u k i y o z \bar{o} s h i$. This genre includes essays, short stories, travel guidebooks, military and religious records - explaining the principles of Buddhism and Confucianism and also criticism of the system and/or society. The multitude of subjects and their approach placed them on a superior level to the previous otogizosshi. The books had pictures on one side and text on the other. They were not signed, but it is generally known that they were written by priests and samurai.

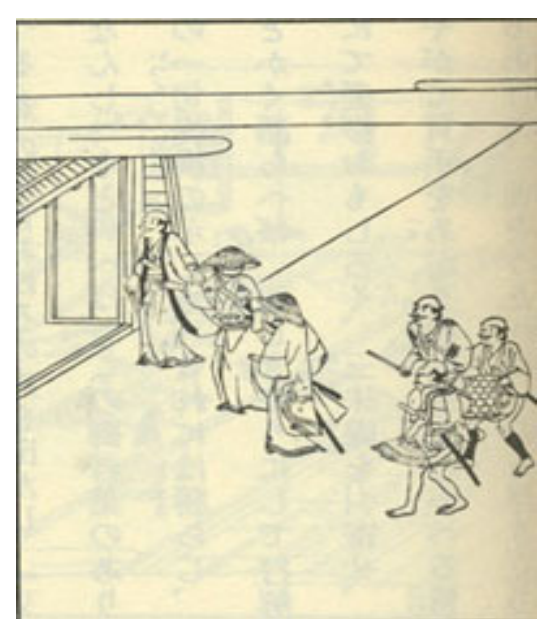

Fig.3.

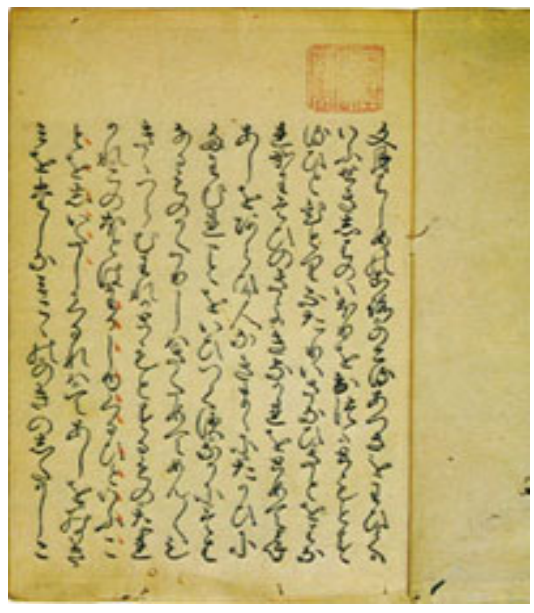

Fig.4.

Fig.3. Illustration "Ukiyo monogatari "(1661) (Source: http://en.wikipedia.org/wiki/Kanazoshi)

Fig. 4. One page of "Denbu monogatari"(1650)(Source: http://en.wikipedia.org/wiki/Kanazoshi)

Ukiyozōshi (浮世草子), “books of the floating world”) was the first kind of popular Japanese literature, developed during the years 1680 and 1770 in Kyōto and Ōsaka. Ukiyozōshi are based on kanazosshi and developed via them, although, of course, at a superior level. The term ukiyozosshi first appeared in 1710 referring to works that had amorous or erotic themes, but then it started to broaden and include a wide variety of subjects and aspects of life in the Edo period. Ihara Saikaku's book, "The Life of a Libertine" is considered the first work of its kind. This brought to the fore the criticism of courtesans and it represented also a guide to the 'pleasure' neighbourhoods that had become popular in the years 1640-1650. Even though the works of Saikaku were not too popular in his own time, they eventually gained great popularity and finally were considered a key to the development and spread of ukiyozoshi. Furthermore, ukiyozōshi literature was vernacular, being written in kana, in contrast to the elite literature, kanbun, which was written in classical Chinese or Japanese and focused more on traditional or aristocratic themes. Ukiyozoshi covered a variety of topics, but many of these were considered vulgar or unworthy of elite literature. However, one of its important features 
was the presence of intense realism, and "direct expression, sometimes ironic, was made in an objective, detached"(Itasaka, 1993, p.126), or cynical manner.

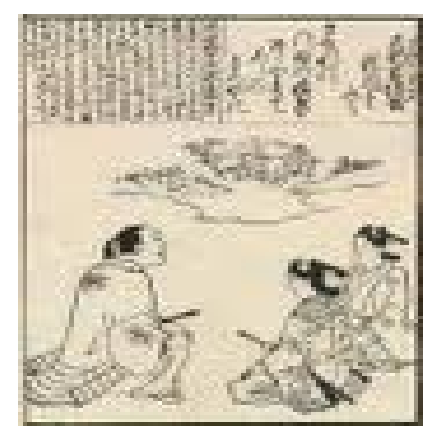

Fig. 5.

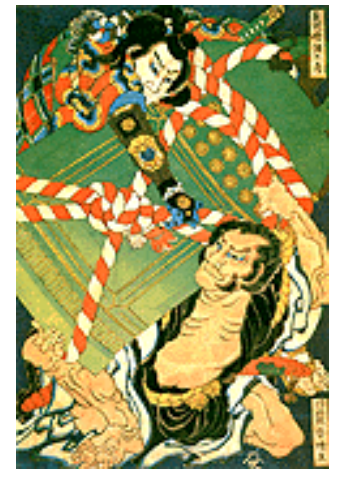

Fig. 6.

Fig.5. "The Life of a Libertine", Ihara Saikaku (1686) (Source: http://it.goldenmap.com/Ihara_Saikaku)

Fig. 6. "Tales of Samurai Honor", Ihara Saikaku (1688) (Source: http://it.goldenmap.com/Ihara_Saikaku)

Kusazosshi (草双紙) is a term that refers to several types of Japanese popular literature genre, with illustrations printed using the technique of "woodblock" in the Edo period and early Meiji period vii. The first Kusazōshi books, published before 1775, contain akahon ("Red Books" for children and less educated people), kurohon and aohon ("Black Books" and "Blue Books", for adults). As we can see, the names are symbolic - aka (red), kuro (black), ao (blue) and the covers of book bear the colour of its name. During this historical period, paintings were considered more important than the text itself. They contained information on the traditions, customs and common elements of everyday social life. Koikawa Harumachiviii, with Kinkin eiga sensei no yume ("The Master Kinkin's Splendid Dream" - kin meaning here "gold"), in 1775, marked a new beginning in the development of kusazōshi literature, creating a new genre, kibyōshi. This new genre, much appreciated by mature and educated men, changed the course of kusazōshi literature. Kibyōshi books had yellow covers and were printed in a series of two or three volumes of 10 pages. They were considered the first adult comics of Japanese literature and contained a fairly large-sized image on each page, and the picture blanks were filled with dialogue and descriptive prose: "The harmony between image and text was remarkable" (Itasaka, 1993, p. 81). Kibyōshi were known for satirizing and criticising contemporary society, subjects focused on urban culture, the state of affairs in the districts of pleasure and last but not least, on the actions of the shogunate (they often used to criticize the devaluation of silver coins, neo-Confucian policies, the leaders' inability to obtain necessary food etc.). That's why the Tokugawa Shogunate banned them, and finally they changed into gōkan, published during the years 1807-1888. These had small images, the main information appeared in text, and they were focused on cultural issues. 


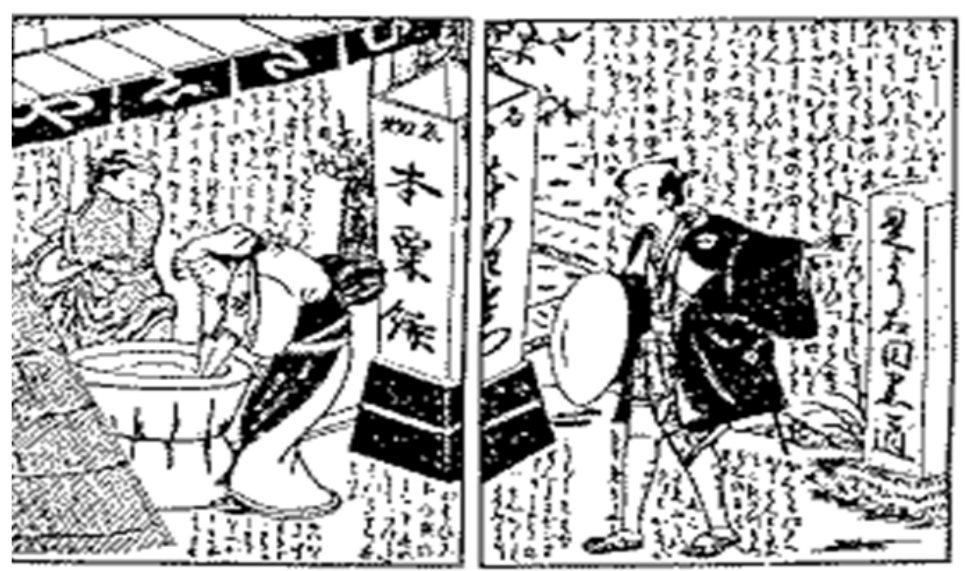

Fig. 7. Kinkin sensei eiga no yume, Koikawa Harumachi (1775) (Source: http://www.tnewfields.info/sb/koi.htm)

We've therefore seen that the image represents a defining element in the understanding of Japanese language and literature, and its exploitation by literary and linguistic means may have reached its maximum. Image, literature and linguistics are in a permanent relationship of interdependence and contextuality. Through literature, there are images you can see or imagine, and through linguistics, literature can express accurately an image exactly as the author wants to convey it.

\section{Endnotes:}

${ }^{\mathrm{i}}$ Heian Period (795-1185) classical Japanese art and culture.

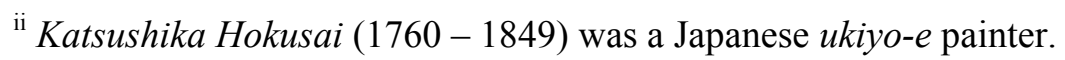

* ukiyo-e, "pictures of the floating world" is a genre of paintings, lithographs and Japanese art made of blocks of wood between the 17th century and the 20th century, of which the leitmotif is represented by landscapes, historical themes or scenes of drama and pleasure.

iii Kanji can be read in two ways. These two types of readings are onyomi and kunyomi, or reading (yomi) 'on' (Chinese), and reading (yomi) 'kun' (Japanese).

The Japanese language did not have written symbols until the introduction of kanji, from China, in the 5th century. Then kanji were simplified into phonetic symbols known as hiragana (a syllabary used for words of Japanese origin for which there is no kanji) and katakana (a syllabary used to write words of foreign origin already in the current language or not, onomatopoeia, or stylistically, instead of kanji and hiragana to put extra emphasis on some words). Thus, the Japanese language came to be written in a combination is of kanji and kana. The combined writing system kanji-kana (a common name for hiragana and katakana) is more effective than the simple one, kana, since when writing in the Japanese language no spaces between words are allowed and inserting kanji among kana can facilitate the reader to distinguish all the words. Moreover, when looking at a book, newspaper, or magazine kanji are of great help in understanding rapidly the main ideas of a text in a certain context. The accompanying smaller kana written above kanji (called furigana) are sometimes used to indicate the correct pronunciation. 
iv The Yin and Shang Dynasty (Shāng Cháo) was the first imperial dynasty of the Chinese Empire leading the region in the north-eastern part of China, in the Valley of the Yellow River. In accordance with the traditional chronology, the Shang Dynasty ruled China between 1766 BC and 1122 BC and according to the shorter timeline based on the Bamboo Annals, between 1556 BC and 1046 BC.

${ }^{\mathrm{v}}$ Edo period or Tokugawa period (1603-1868)

${ }^{\text {vi }}$ Ihara Saikaku (1642-1693) was a Japanese poet and creator of the "floating world" genre of Japanese prose ukiyozōshi.

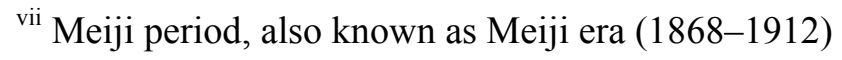

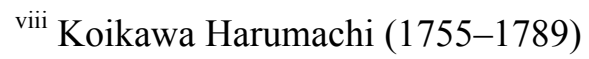

\section{Works cited:}

Itasaka, G., 1993. Gogen no Nihon shi tanken, Dobun Shoin; Dai 1-han edition.

Nishiguchi, Koichi and Kono, T., 1994. Kanji in Context, Japan Times Publishing House, Tōkyō.

Sandra-Lucia Istrate, $P h D$

Hyperion University of Bucharest

Romanian-Japanese Studies Center

Romanian-American University

istratesandralucia1976@gmail.com

Publication of the article was supported by a grant of the project KEGA 039UKF-4/2012 Vyučovanie súcasných anglofónnych literatúr ako prostriedok posilňovania kreativneho a kritického myslenia. 